\title{
OJS OPEN

\section{FORMAÇÃO DE PROFESSORES: PROGRAMAS UNIVERSITÁRIOS NA FORMAÇÃO INICIAL EM GEOGRAFIA}

\author{
Marcos Gomes de Sousa ${ }^{1}$, Rodrigo de Sousa Freitas ${ }^{2}$, Raimundo Lenilde de Araújo ${ }^{3}$
}

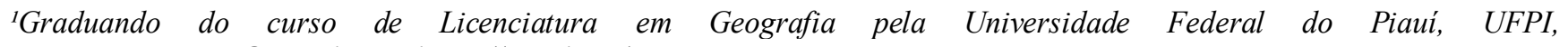
marcossggomes77@gmail.com, https://orcid.org/0000-0002-7421-3768

${ }^{2}$ Graduando do curso de Licenciatura em Geografia pela Universidade Federal do Piauí, UFPI, rodrigodesousa511@gmail.com,https://orcid.org/0000-0003-3335-3032

${ }^{3}$ Universidade Federal do Piauí (UFPI). Doutor em Educação Brasileira e Mestre em Desenvolvimento e Meio Ambiente (UFC). Especialista em Ensino de Geografia e Graduado em Geografia - Licenciatura (UECE). Professor Efetivo, Classe Associado I, da Universidade Federal do Piaui (UFPI), no Curso de Licenciatura em Geografia e no Programa de PósGraduaçãoem Geografia, raimundolenilde@ufpi.edu.br,https://orcid.org/

0000-0002-5491-0996
\end{abstract}

Artigo recebido em 26/06/2021 e aceito em 10/10/2021

\begin{abstract}
RESUMO
É notório perceber o quanto a discussão sobre a formação de professores vem sendo debatida nos últimos anos, sobretudo, na Formação Inicial. Desse modo, torna-se importante realizar uma análise dos projetos e programas presentes nas instituições de Ensino Superior (IES) na formação inicial de futuros professores de Geografia. Nesse sentido, o referente artigo tem como objetivo geral apresentar os programas presentes na formação inicial, tendo também como objetivo específico discutir a importância deles nas IES como a Extensão Universitária, Programa Institucional de Bolsas de Iniciação à Docência (PIBID), Residência Pedagógica (RP) e as Monitorias de Disciplinas, que oportunizam uma formação eficiente, crítica e dinâmica, engendrando assim, futuras práticas pedagógicas mais reflexivas, pois elas constituem a base para uma formação de qualidade. O estudo baseou-se em revisões bibliográficas acerca da temática central, a partir da qual foi possível analisar artigos, livros e obras que proporcionaram o entendimento da temática em questão. A pesquisa torna-se importante, porque discute e aborda questões qualitativas dos programas e projetos institucionais, apresentando suas potencialidades na formação inicial em Geografia, viabilizando aos futuros professores a oportunidade de vivenciarem novas experiências, tanto nas escolas quanto na própria universidade. Ou seja, os programas abordam os conhecimentos teóricos e práticos necessários para formação de qualidade na prática docente. Assim sendo, o acesso ao conhecimento que é transmitido de professor para aluno torna-se mais estimulante e atraente quando se tem acesso a tais programas institucionais.
\end{abstract}

Palavras-chave: Professor; Geografia; Formação Inicial; Ensino; Programas universitários. 


\title{
TEACHER EDUCATION: UNIVERSITY PROGRAMS IN INITIAL GEOGRAPHY TRAINING
}

\begin{abstract}
It is notorious to notice how much the discussion about teacher education has been debated in recent years, especially in Initial Education. Thus, it is important to carry out an analysis of the projects and programs present in Higher Education Institutions (HEIs) in the initial training of future Geography teachers. In this sense, the referent article has as general objective to present the programs present in the initial formation, also having as specific objective to discuss their importance in the IES as the University Extension, Institutional Program of Teaching Initiation Scholarship (PIBID), Pedagogical Residency (RP) and the Discipline Monitors, which provide opportunities for efficient, critical and dynamic training, thus engendering more reflective future pedagogical practices, as they constitute the basis for quality training. The study was based on bibliographical reviews about the central theme, from which it was possible to analyze articles, books and works that provided an understanding of the theme in question. The research becomes important because it discusses and addresses qualitative issues of institutional programs and projects, presenting its potential in initial training in Geography, providing future teachers with the opportunity to experience new experiences, both in schools and in the university itself. That is, the programs address the theoretical and practical knowledge needed for quality training in teaching practice. Therefore, access to knowledge that is transmitted from teacher to student becomes more stimulating and attractive when one has access to such institutional programs.
\end{abstract}

Keywords:Teacher. Geography. Initial formation. Teaching. UniversityPrograms.

\section{FORMACIÓN DEL PROFESORADO: PROGRAMAS UNIVERSITARIOS DE FORMACIÓN INICIAL EN GEOGRAFÍA}

\begin{abstract}
RESUMEN
Es notorio notar cuánto se ha debatido la discusión sobre la formación del profesorado en los últimos años, especialmente en Educación Inicial. Por ello, es importante realizar un análisis de los proyectos y programas presentes en las Instituciones de Educación Superior (IES) en la formación inicial de los futuros profesores de Geografía. En este sentido, el artículo de referencia tiene como objetivo general dar a conocer los programas presentes en la formación inicial, teniendo además como objetivo específico discutir su importancia en las IES como la Extensión Universitaria, Programa Institucional de Becas de Iniciación Docente (PIBID), Residencia Pedagógica (RP) y los Monitores de Disciplina, que brindan oportunidades para una formación eficiente, crítica y dinámica, generando así prácticas pedagógicas futuras más reflexivas, ya que constituyen la base de una formación de calidad. El estudio se basó en revisiones bibliográficas sobre el tema central, a partir de las cuales fue posible analizar artículos, libros y trabajos que permitieron comprender el tema en cuestión. La investigación adquiere importancia porque discute y aborda temas cualitativos de programas y proyectos institucionales, presentando su potencial en la formación inicial en Geografía, brindando a los futuros docentes la oportunidad de vivir nuevas experiencias, tanto en las escuelas como en la propia universidad. Es decir, los programas abordan los conocimientos teóricos y prácticos necesarios para una formación de calidad en la práctica docente. Por lo tanto, el acceso al conocimiento que se transmite de maestro a alumno se vuelve más estimulante y atractivo cuando se tiene acceso a dichos programas institucionales.
\end{abstract}

Palabras clave: Docente. Geografía. Formación inicial. Enseñando. Programas universitarios 


\section{INTRODUÇÃO}

São amplos os desafios enfrentados por graduandos dos cursos de licenciaturas nas universidades brasileiras, e no curso de Geografia não seria diferente. Manter-se atualizado sobre os avanços tecnológicos e as práticas pedagógicas no contexto escolar de forma eficiente faz com que muitos alunos de licenciaturas busquem novas maneiras de adquirir aprendizagens e novas experiências em sala de aula, muitas vezes antes mesmo da atuação profissional. Dessa forma, os programas de Formação Inicial tornam-se importantes para a prática docente crítica, reflexiva e qualitativa.

Torna-se essencial analisar os programas nas universidades como a Extensão Universitária, Programa Institucional de Bolsas de Iniciação à Docência (PIBID), Residência Pedagógica (RP) e as Monitorias de Disciplinas, pois estes viabilizam diferentes saberes na formação de futuros profissionais, principalmente, no que se refere à teoria e à prática. Além disso, são os principais programas em muitas instituições públicas. Santos, Menezes e Bento (2020, p. 89) afirmam que:

Nessa situação, a formação docente precisa ser pensada a partir da integração teórica e prática, pois qualquer iniciativa diferente, como pensar teoricamente uma situação e excluir sua prática e vice-versa, provoca a exclusão de parte do processo, limitando, assim, a compreensão da totalidade.

A discussão neste artigo torna-se importante, pois debate as concepções e a importância dos programas institucionais para a formação de futuros professores em Geografia, tendo em vista que oportunizam experiências nas escolas e na própria universidade (Federais e Estaduais), ou seja, abordam os conhecimentos teóricos e práticos necessários para formar professores reflexivos, autônomos e que sejam experientes em sala de aula. Diante disso,Ferro e Guedes (2018, p. 23) mencionam que "o profissional reflexivo constrói o seu próprio conhecimento profissional".

Para mediar e produzir saberes de qualidade e de forma eficiente, a formação docente podeestar relacionada à qualificação acadêmica atualizada, tendo em vista a necessidade de aprender conteúdo teórico, metodológico e pedagógico. Nesse contexto, possibilita a formação de profissionais de boa qualidade com capacidade de associar teoria e prática e desenvolver o diálogo e a relação com os alunos para se compreender a realidade da sala de aula.

O trabalho teve como objetivo geral apresentar os programas presentes na formação inicial do curso de Geografia da Universidade Federal Piauí (UFPI), tendo como objetivos específicos: discutir a importância dos programas nas IES, a exemplo da UFPI, como a extensão universitária, Programa Institucional de Bolsas de Iniciação à Docência (PIBID), Residência Pedagógica (RP) e Monitoria de Disciplina, estas viabilizam a formação eficiente, crítica e dinâmica, o que possibilita práticas pedagógicas reflexivas e se constituem como base para a formação de boa qualidade.

O estudo fundamentou-se em revisões bibliográficas acerca da temática central, em que foi 
possível analisar artigos, publicações em periódicos e livros, sendo elas importantes para aelaboração e execuçãoda pesquisa. Obras dos autores como Tardif (2010), Silva (2019), que discutem respectivamente, os saberes docentes e a formação continuada de professores de Teresina, foram essenciais para o desenvolvimento e execução do trabalho.

Para a realização, desenvolvimento e efetivação da discussão, dois questionamentos foram essenciais para a pesquisa: qual a importância e os principais desafios que os discentes vivenciam ao participarem dos programas institucionais? E quais são as vantagens que os discentes adquirem ao participar de tais programas em sua formação inicial? Nessas perspectivas, têm-se como hipóteses que os programas são importantes, porque permitem aos discentes vivenciarem a realidade escolar, antes de sua atuação profissional, e um dos maiores desafios está relacionado com a falta de recursos financeiros para áreas de humanas, pois tais recursos tornam-se essenciais para o desenvolvimento de pesquisas. Dessa forma, o aprender-ensinar por meio desses programas é essencial e se concentra em dois pilares: o próprio discente participante, como agente, e a instituição de ensino como o lugar de crescimento profissional permanente.

A formação docente, nesse sentido, relaciona-se à ideia de aprendizagem constante no sentido de provocar inovação na construção de novos conhecimentos que darão suporte teórico e prático ao trabalho docente. Ressalta-se, portanto, a grande importância dos programas nas universidades, pois é a partir deles que os discentes, enquanto futuros profissionais da educação poderão explorar e desenvolver todo o conhecimento científico produzido ao longo de sua formação inicial. Acrescenta-se a isso, a relação de que os pilares das universidades são: o ensino, a pesquisa e a extensão. E nesse contexto, os programas e projetos pedagógicos nos cursos de licenciaturas são vistos como forma de preparar os discentes para e na sala de aula, o que torna mais eficaz o vínculo entre teoria e prática, bem comooelo da universidade e a escola, e ainda a melhoria e o aperfeiçoamento das formas de ensino e aprendizagem nas instituições de ensino (universidades e escolas).

\section{PROGRAMAS E PROJETOS PARA A FORMAÇÃO DOCENTE}

Cada docente não é visto apenas como um mero facilitador(a) e transmissor(a) de conteúdos, mas como mediador(a) no processo de ensino e aprendizagem no contexto escolar, e é responsável por formar indivíduos capazes de opinar e pensar de forma autônoma sobre vários assuntos. Bulgraen (2010, p. 31) afirma que "[...] o professor deve se colocar como ponte entre o estudante e o conhecimento para que, dessa forma, o aluno aprenda a "pensar" e a questionar por si mesmo [...]”.Cabe, portanto, ao professor não apenas transmitir os conhecimentos de forma passiva, mas contribuir para a construção de cidadãos pensantes. 
Desse modo, a participação de discentes em programas institucionais torna-se imprescindível para a formação de profissionais mais competentes, o que possibilita a capacitação de professores com olhares aguçados e com muita vontade de ensinar. A qualificação do aluno para o trabalho docente se constitui em um ato educativo de criatividade e de renovação, que contribui para a formação do(a)docente mais qualificado para ensinar. Com isso, Silva (2019, p. 24) afirma que:

A formação inicial do professor significa o começo de um percurso a ser trilhado pelo profissional, é uma fase de aprendizagem e troca de informações, de aquisição de experiências diante de atividades práticas como o estágio supervisionado e as práticas pedagógicas interdisciplinares presentes em alguns currículos dos cursos de formação. Além disso, é uma fase de constantes interações sociais entre professores formadores e os futuros profissionais.

Entende-se, assim, que ser educador(a) é educar-se constantemente por meio de projetos e programas universitários, pois eles possibilitam um aprendizado no qual o conhecimento construído é resultado das relações de experiências e das novas habilidades adquiridas ao longo da permanência nos programas acadêmicos. Ademais, idealiza o engajamento e novas práticas pedagógicas além de manter qualitativamente a formação de professores mais dinâmica e atraente.

O profissional da educação se renova todos os dias fundamentados em várias perspectivas, como por exemplo, o instinto a curiosidade, a inquietação e a pesquisa e, principalmente, a interação em sala de aula. E, nesse sentido, Tardif (2020, p.49) afirma que "o docente raramente atua sozinho. Ele se encontra em interação com outras pessoas, a começar pelos alunos". Além disso, é necessário que haja a preocupação com o desenvolvimento da ação educativa que seja capaz de preparar e auxiliar os(as) discentes para que estes possam compreender as transformações na escola, além de despertar pensadores críticos, autônomos e que sejam facilitadores de aprendizagens, ou seja, o desenvolvimento de um bom professor. Nunes e Lima (2018, p. 61) mencionam que:

O conceito de "bom professor", mesmo no sistema tradicional, varia e tem variado. Este fato se deve ao nível de esclarecimento das pessoas. Quando se trata de uma clientela bem atendida por aparato científico-pedagógico, a tendência é que exija um professor que se afaste do perfil de professor clássico, tendo em vista que a exigência e o conceito de "bom professor" representam um educador que tenha uma postura mais flexível diante dos alunos, assumindo-se como um facilitador da aprendizagem.

\subsection{EXTENSÃO UNIVERSITÁRIA}

Participar de forma ativa na formação inicial implica afirmar que osgraduandos(as) dos cursos de licenciaturas podem participar de programas e projetos de extensão presentes na própria universidade, haja vista que elas tornam-se grandes aliadas para o processo formativo do futuro profissional crítico e reflexivo acerca da realidade social. Sousa (2020, p. 112), ao discutir sobre a extensão universitária, afirma que "as atividades de extensão possibilitam diálogos entre a universidade e a sociedade, 
proporcionando aos futuros professores um olhar mais crítico e reflexivo acerca da realidade escolar".

As atividades de extensão estimulam os licenciandos a buscar métodos para uma conjunção de atividades realizadas em campo, seja ela dentro da própria universidade ou no âmbito escolar, por meio de pesquisas e pelo gosto pelo ensinar e o aprender. Faz-se necessário que estes sujeitos formadores, reconheçam e internalizem em si a importância e à proporção que atinge o seu papel na vida dos envolvidos, para que, também se sintam motivados para a realização das atividades que lhe competem.

A extensão universitária aplica novas formas de aprendizagens por intermédio de projetos que permitem o diálogo com a comunidade escolar, tendo em vista que é por meio da extensão que ocorre uma das possibilidades da materialização do saber acadêmico. A extensão permite novas experiências de práticas pedagógicas, de analisar de forma crítica e reflexiva o ambiente escolar. Assim como nas atividades extensionistas do curso de Geografia da UFPI no município de Teresina, Piauí, vivenciado no ano de 2021 com a temática central Educação ambiental em escolas de Educação Básica.

O trabalho foi realizado pela disciplina Atividade Curricular de Extensão 5 (ACE 5) no período 2020.2, referente ao ano de 2021. A atividade teve como temática secundária "a educação ambiental e tecnologia: uso de jogos digitais como proposta didático-pedagógica" que foi ministrada pelos discentes do curso de licenciatura em Geografia da UFPI durante a modalidade do Ensino Remoto Emergencial (ERE). Ao longoda discussão da proposta foram apresentados três jogos digitais queabordam a temática educação ambiental, como por exemplo, Trilha Ecológica, O Piquenique do Itamar e o Defensor da Natureza (Figura 1):

Figura 1 - Apresentação da palestra proferida pelos discentes do curso de Geografia da UFPI acerca dos jogos digitais relacionados com a educação ambiental na atividade de extensão, 2021.

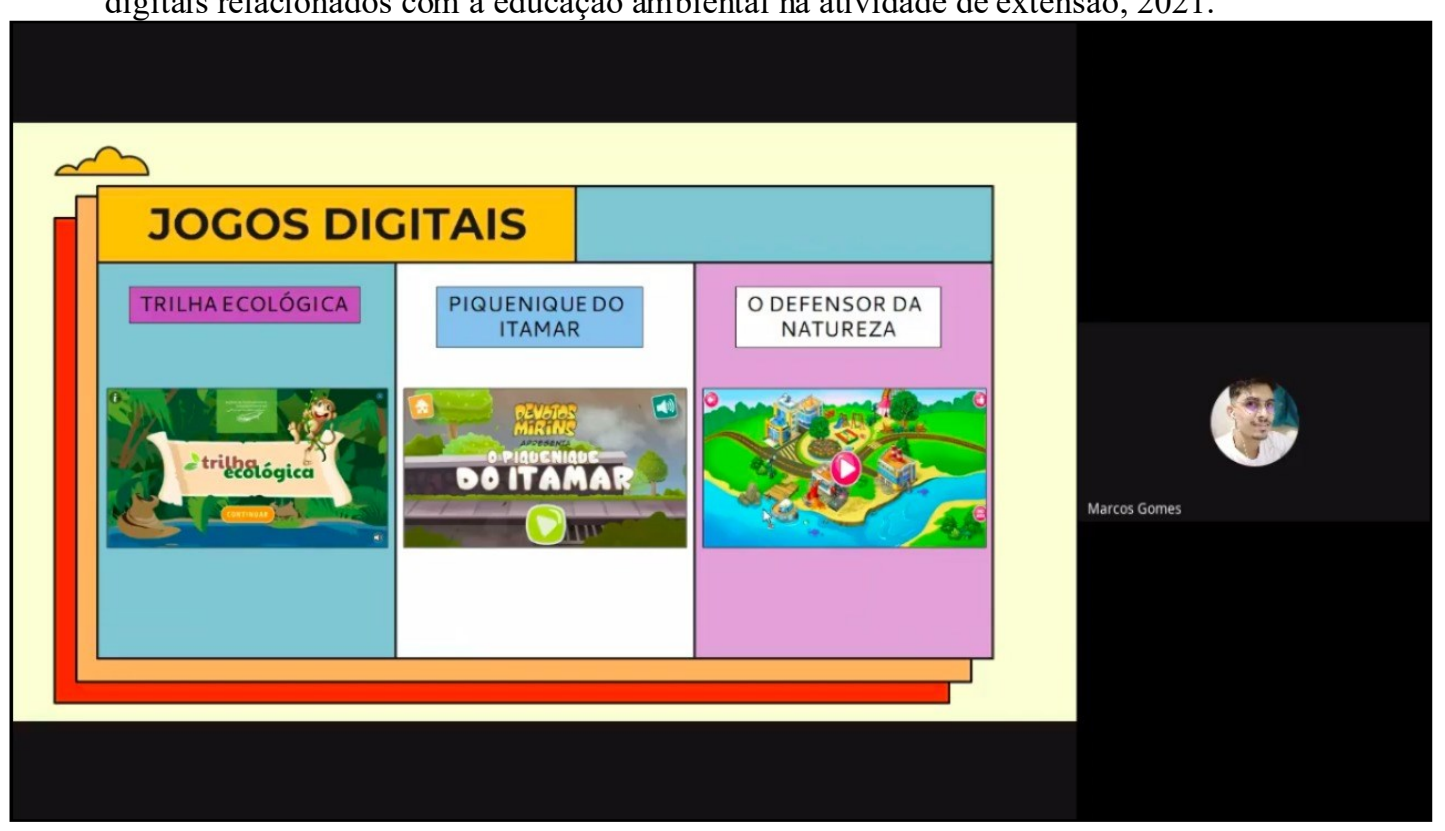

Fonte: Autores (2021) 
A atividade proposta contribuiu para inserir temas e conceitos relacionados com a educação ambiental. Dessa forma, os jogos denotam a importância do meio ambiente e sua preservação, o funcionamento dos sistemas, a degradaçãoda natureza e o respeito mútuo aosecossistemas. Conclui-se, portanto, que os jogos digitais se tornaram grandes potencializadores, tanto na prática da extensão quanto da aprendizagem dos alunos.

O processo de ensino e aprendizagem idealizado por meio de projetos extensionistas, portanto, visa preparar o licenciando para o fazer docente, tendo em vista que o conhecimento e realidade vivenciados nas escolas e na própria universidade os auxiliam com novas experiências e aprendizagens. Fica em evidência a importância que a extensão universitária tem na vida acadêmica e profissional dos discentes, pois eles terão o discernimento de suas práticas pedagógicas na escola.

\subsection{PROGRAMA INSTITUCIONAL DE BOLSAS DE INICIAÇÃO À DOCÊNCIA (PIBID)}

Assim como as atividades de extensão, o Programa Institucional de Bolsas de Iniciação à Docência - PIBID contribui como grande auxiliador e impulsionador de novas experiências em sala de aula. Nesse sentido, Sousa e Albuquerque (2019, p. 109) conceituam o PIBID como "um programa que possibilita aos integrantes vivenciar a realidade escolar ainda na graduação, proporcionando-lhes um exitoso processo de formação à docência”. Outro conceito acerca desse programa é definido pela Coordenação de Aperfeiçoamento de Pessoal de Nível Superior - CAPES (2020), a qual o define como:

O PIBID é um programa da Política Nacional de Formação de Professores do Ministério da Educação (MEC) que visa proporcionar aos discentes dos cursos de licenciatura sua inserção no cotidiano das escolas públicas de educação básica. Para o desenvolvimento dos projetos institucionais de iniciação à docência, o programa concede bolsas aos licenciandos, aos professores das escolas da rede pública de educação básica e aos professores das IES.

Conforme o Decreto n 7.219 de 24 de junho de2010(BRASIL, 2010), o Programa Institucional de Bolsas de Iniciação à Docência - PIBID, executado no âmbito da Coordenação de Aperfeiçoamento de Pessoal de Nível Superior - CAPES tem por finalidade fomentar a iniciação à docência, contribuindo para o aperfeiçoamento da formação de docentes em nível superior e para a melhoria de qualidade da educação básica brasileira.

O programa foi criado em meados do segundo semestre de 2007, concedido pelo Conselho Nacional de Desenvolvimento Científico e Tecnológico (CNPQ), porém tendo como responsável a CAPES. Sousa e Albuquerque (2019, p. 109) mencionam que "O PIBID tem como objetivos incentivar e qualificar a formação de estudantes que optaram pela carreira docente, seja do curso de Geografia ou de outras licenciaturas". Ademais, tem o intuito de contribuir para a valorização do magistério, elevar a qualidade na formação inicial de professores e colaborar para a articulação entre teoria e prática 
necessária a formação docente (CAPES, 2020).

A partir desses argumentos, percebe-se a importância que o PIBID possui para o desenvolvimento profissional do futuro professor em Geografia. O papel da universidade quanto à formação de professores demanda que, em qualquer que seja o nível educacional (superior e escolar), deve haver a articulação e o comprometimento com todo o conjunto de forma sistemática. A universidade, dessa maneira, possui o papel de apresentar meios indispensáveis para a composição e qualificação de um bom profissional, sobretudo, aqueles que optaram pela carreira docente.

Sousa e Albuquerque (2019, p. 109) afirmam que "tal programa surgiu como uma forma de melhorar a formação de professores e, consequentemente, a qualidade na educação básica”. Dessa forma, o programa PIBID foi criado como um programa para impulsionar o processo de ensino e aprendizagem dos participantes e estimular a prática docente.

Ainda de acordo com Sousa e Albuquerque (2019, p. 109) "neste contexto, o PIBID permite realizar trocas dos saberes acadêmicos e escolares, de modo que os integrantes do programa possam refletir e pensar atividades para o cotidiano escolar, tendo como lócus de atuação a educação básica". Nesse caso, o processo de aprendizagem é o momento de encontro entre a teoria e prática na escola, com os alunos e com o cenário que irá atuar durante sua vida profissional.

O PIBID possibilita aos discentes dos cursos de licenciaturas vivenciarem a realidade de muitas instituições de ensino básico, a adquirir novas práticas pedagógicas, incentiva a Formação Inicial e contribui na articulação entre teoria e prática. $\mathrm{O}(\mathrm{a})$ futuro(a)docente, nesse contexto, não será apenas um(a) mero(a) transmissor(a) de conteúdos, tendo em vista que o programa foi criado para contribuir com uma formação mais eficiente e de qualidade.

Além disso, tal programa tornou-se um grande incentivador para a permanência dos discentes no curso, uma vez que sua inserção como pibidianosse dá na fase inicial de sua graduação,mas vale ressaltar que o programa é limitante em relação a seleção dos participantes, pois há um número limitado de vagas, que por sua vez oferta oportunidades para atuação como aluno-bolsista e ou voluntário.Nesse sentindo, muitos licenciandos não conseguem se integrar ao programa porque muitas vezes a seleção é criteriosa e concorrida, alguns destes só apresentam, em sua maioria, o primeiro contato com a prática docente por meio de outros programas universitários.

O PIBID é de suma importância, uma vez que ocorre a aproximação da universidade com as escolas, no sentido de contribuir para a formação docente e de propiciar, aos discentes participantes, a oportunidade de colocar, em prática, tudo que foi aprendido na universidade. À vista disso, uma parcela do(a)s graduando(a)s do curso de Geografia da UFPI realizou ao longo de 2018 a 2020 atividades nas escolas da rede pública de ensino, no munícipio de Teresina/Piauí. A exemplo da participação dos autores 
em duas unidades escolares, Colégio Estadual Zacarias de Gois (Liceu Piauiense) e Centro Estadual de Tempo Integral Governador Dirceu Mendes Arcoverde - Colégio da Polícia Militar do Piauí (CPMPI).

Durante a participação nas escolas foram elaboradas ações interventivas, como a criação do Projeto de Exposição de Maquetes (EXPOGEO) com os alunos da $1^{\mathrm{a}}$ série do ensino médio no Colégio Liceu Piauiense, o projeto visou estimular o desenvolvimento cognitivo por meio da produção de maquetes, sobretudo, no âmbito da Geografia Física, que possibilitou ainda aos alunos, a prática da exposição oral do conteúdo ensinado na sala de aula. Ademais, os pibidianos foramessenciais durantea mediação, pois puderam vivenciar a realidade escolar e todas as etapas do projeto, desde a elaboração até a sua execução (Fotografia 1):

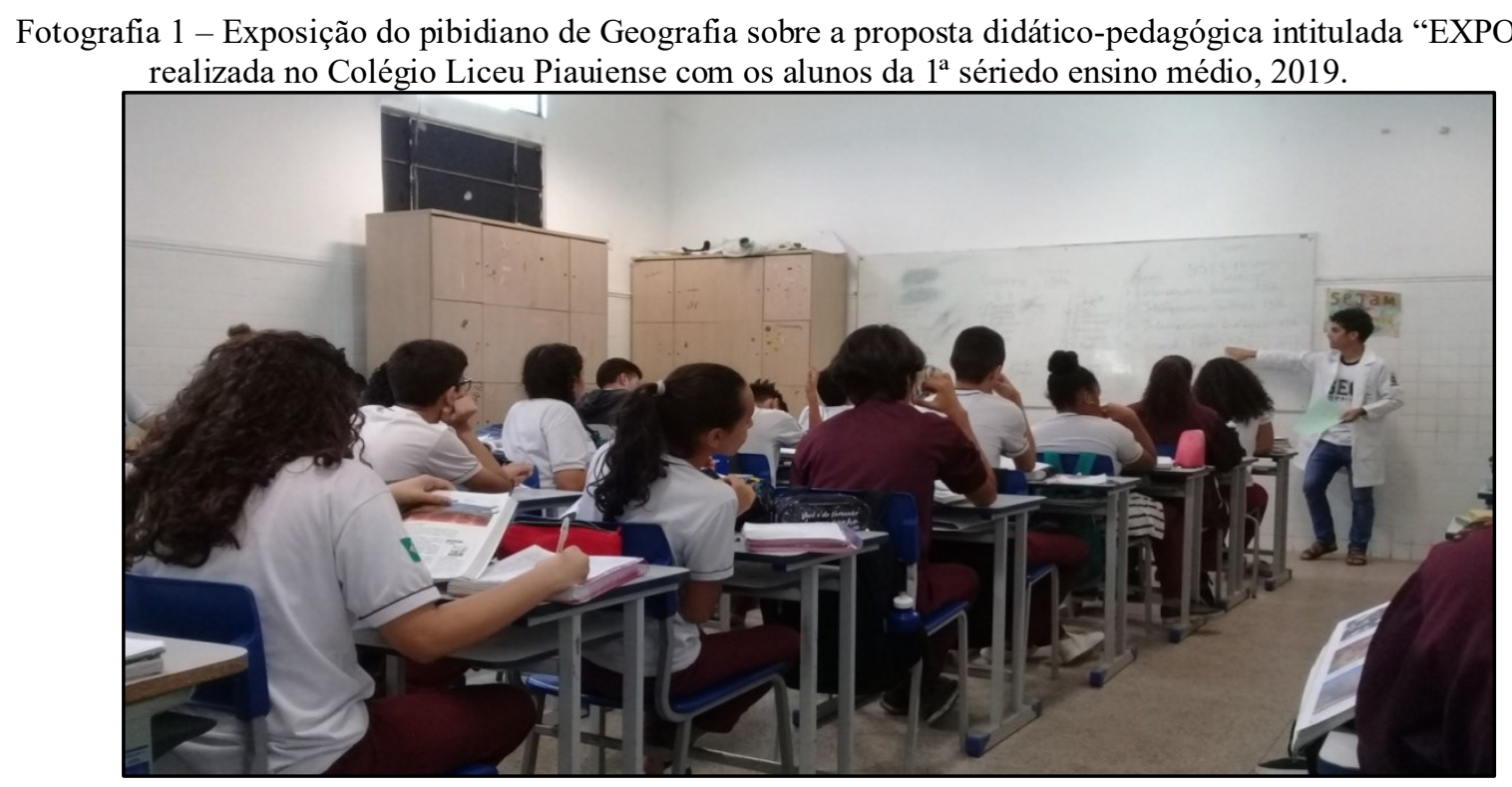

Fonte: Sousa, 2019.

Outra proposta idealiza por intermédio do PIBID, foi o projeto "ENEM 2020", que proporcionou a revisão de conteúdos de Geografia relacionada ao Exame Nacional do Ensino Médio (ENEM), com as turmas de $3^{\mathrm{a}}$ série do ensino médio do CPMPI. A atividade contou com aplicação de resoluções e elucidação de questões das edições anteriores do exame, este que é uma das formas de ingresso para muitas Instituições de Ensino Superior (IES). Os pibidianos da Geografia UFPI puderam acompanhar as turmas desde o início do período letivo até a aplicação da prova e, consequentemente, seus resultados. Nesse sentido, o projeto foi bastante relevante, pois sempre esteve incentivando os alunos e ajudando na compreensão de conteúdos e assuntos atuais da Geografia.

No decorrer das resoluções foram caracterizadas pequenas dúvidas por parte dos alunos acerca dos conteúdos que eles mesmos já haviam estudado, mas que não recordavam. Devido a isso, tornou-se essencial realizar revisões periódicas sobre os conteúdos já vistos em sala de aula, durante a aplicação da 
resolução das questões, isso graças ao projeto "ENEM 2020”. Dessa forma, tal atividade proporcionou aos alunos uma maior sistematização dos principais temas abordados no ENEM, sobretudo, nas ciências humanas, além disso, foi possível incentivá-los ainda mais nos estudos por meio de simulados (Fotografia 2):

Fotografia 2 - Aplicação de simulado para o ENEM 2020 com as turmas de $3^{\mathrm{a}}$ série do ensino médio do CPMPIapós abordagens anteriores de conteúdos de Geografia durante as aulas, 2019.

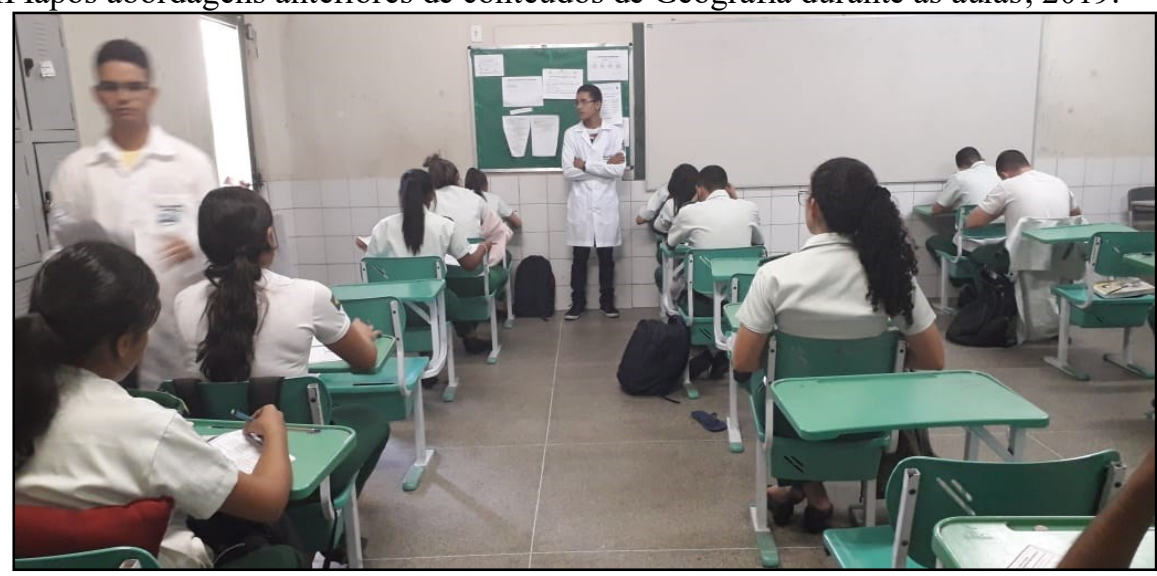

Fonte: Freitas, 2019.

Nesse sentido, oPIBID provocou impacto muito positivo para a formação dos futuros profissionais da educação durante a experiência adquirida em tais projetos pedagógicos nas duas escolas, visto que ao conhecer e enfrentar as dificuldades impostas no dia a dia foi possível uma nova forma de educar com a construção de novas técnicas e metodologias de ensino para tornar mais eficiente o processo de aprendizagem dos alunos das duas escolas participantes.

Portanto, esse programa é uma maneira de fazer com que os discentes participantes encarem os grandes desafios no fazer docente, ao proporcionar melhor a sua formação acadêmica inicial. Além disso, o PIBID possibilita novas experiências e novas práticas docentes, já queo aluno-participante está inserido diretamente no seu futuro local de trabalho.

\subsection{O PROGRAMA RESIDÊNCIA PEDAGÓGICA (RP)}

Outro programa muito importante para o desenvolvimento profissional dos discentes do curso de licenciatura na formação inicial é a Residência Pedagógica (RP), que é um programa que tem como objetivo principal, proporcionar aos alunos de licenciaturas vivenciarem a realidade escolar, ampliar e consolidar a relação das IES com as escolas de ensino básico. Freitas, Freitas e Almeida (2020, p. 2) mencionam que:

O PRP é uma iniciativa, voltada para a formação inicial de professores, oportunizando os alunos dos cursos de licenciaturas, a vivência da profissão, de forma dinâmica, com uma duração de $440 \mathrm{~h}$ de práxis pedagógica, conhecendo a escola com mais precisão, desenvolvendo habilidades de um professor reflexivo e atuante. 
O RP foi criado, portanto, a partir da necessidade de aperfeiçoar e assegurar novas habilidades e competências pedagógicas aos residentes ao longo de sua participação no programa.A formação docente requer atenção especial no que diz respeito à prática em sala de aula e é por meio do RP que esse contato nas escolas cria a conexão entre teoria e prática. Além desse contato, a Residência Pedagógica proporciona o conhecimento essencial para a formação intelectual, social e profissional do discente residente. Nesse sentido, a Coordenação de Aperfeiçoamento de Pessoal de Nível Superior - CAPES (2020) menciona que:

O Programa de Residência Pedagógica é uma das ações que integram a Política Nacional de Formação de Professores e tem por objetivo induzir o aperfeiçoamento da formação prática nos cursos de licenciatura, promovendo a imersão do licenciando na escola de educação básica, a partir da segunda metade de seu curso.

Nesse sentido, pode-se afirmar que o processo de aprendizagem dos graduandos está relacionado com o tripé: formação, participação e experiência. Os projetos e programas vinculados aos docentes com formação em andamento na universidade são de grande importância, pois eles proporcionam incentivos para exercer a profissão e, ao mesmo, tempo motiva os discentes a criarem rotinas de estudos para atuar futuramente em sala de aula com mais sutileza.

O programa Residência Pedagógica assim como o PIBID, foi criado como forma de enriquecer o processo de formação inicial de futuros professores e possibilitar aos participantes vivenciarem novas realidades no contexto escolar. Porém, o RP permite, de forma prática, ministrar aulas de modo supervisionado. Nesse caso, os residentes podem empregar novos recursos, técnicas e metodologias de ensino na escola a qual estão alocados.

O programa foi implementado, conforme a Portaria $n^{\circ} 38$, de 28 de fevereiro 2018 (CAPES, 2018), com o intuito de enriquecer e valorizar a formação docente nas universidades e instituições públicas. Esse programa institucional possibilita ao residente criar planos de aulas, utilizarem métodos e técnicas pedagógicas nas escolas de ensino básico. Destaca-se também o grande potencial que ela possui para a reflexão da prática docente, das dificuldades no ensino e, consequentemente, novas soluções para o ensino básico.

Para poder participar desse programa, o aluno deve ter cursado mais de $50 \%$ do curso, diferentemente do PIBID que é destinado aos alunos que estão na primeira metade do curso. Nesse sentido, pode-se perceber o quanto que este programa se torna essencial para o aluno-residente, pois é a partir dela que o aluno lida com as dificuldades presentes nas escolas públicas.

Assim como o PIBID, o RP foi criado como uma forma de melhorar o processo de formação docente de muitas universidades e escolas, propiciando aos residentes novas aprendizagens no âmbito escolar. Freitas, Freitas e Almeida (2020, p. 5) afirmam que “o estudante participa da rotina da escola 
parceira, inclusive das atividades extrassala promovidas pela escola, a partir do plano de atividade elaborado em conjunto". Dessa forma, O RP está intimamente relacionado com a teoria e prática, com o incentivo de professores qualificados e da aproximação da universidade com as escolas.

Durante a participação inicial dos autores no RP da UFPI do curso de Geografia, com duração de 2020 a 2022, com isso foram realizadas várias atividades pedagógicas na escola participante, sendo esta o Colégio da Polícia Militar do Piauí (CPMPI) com as turmas de $1^{\text {a }}$ série do ensino médio, tendo um total de 345 alunos matriculados que estavam distribuídos em 11 turmas. Vale salientar que, a participação no programa se deu de forma remota devido a pandemia da Covid-19, ocasionado pelo vírus Sars-cov-2, nesse sentido, as aulas foram mediadas por intermédio de vários recursos tecnológicos, como por exemplo, uso do Google Classroom, Google Meet, grupos de whatsapp e o uso do livro didático no formato digital.

Dessa forma, foram aplicados aos alunos da referida escola vídeos, jogos e aplicação de aula dialogada. O Google Classroom foi essencial para a criação das turmas (assíncrono), com o propósito de inserir as atividades de fixação e outros materiais complementares ao conteúdo exposto durante as aulas, além disso, foi por meio dessa ferramenta que obtivemos o controle das avaliações aplicadas aos alunos. Em contrapartida, o Google Meet tornou-se um meio alternativo de realizar aulas síncronas, proporcionando aulas dialogadas por intermédio de recursos não convencionais, como por exemplo, aplicação de vídeos, músicas e jogos digitais (Figura 2):

Figura 2 - Momento da regência realizada pelos discentes do curso de Geografia da UFPI, em queutilizou-se

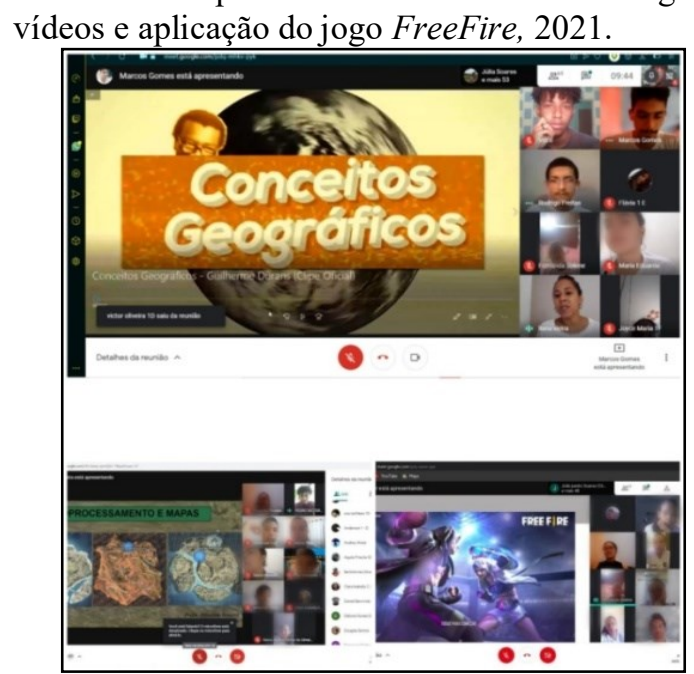

Fonte: Autores (2020)

Levando-se em consideração esses aspectos, podemos ter uma rápida, porém detalhada, análise acerca das ferramentas e plataformas utilizadas para auxiliar no ensino remoto durante a pandemia da Covid-19. Sendo assim, percebem-se como estas são de grande utilidade quando inseridas de forma certa 
no processo de ensino e aprendizagem, denotando ainda as múltiplas possibilidades de sua aplicabilidade, pois muitas são as formas para trabalhar com as Novas Tecnologias Digitais da Informação e Comunicação (NTDICs) no ensino de Geografia mediado pelo RP.

\subsection{MONITORIA ACADÊMICA DE DISCIPLINA}

A monitoria acadêmica de disciplina pode ser considerada como prática pedagógica e uma maneira de facilitar o entendimento de textos acadêmicos, compreensão e assimilação de conteúdo para os alunos e para o próprio monitor, ou seja, o programa institucional possui grande potencial pedagógicoem IES públicas e privadas. Vicenziet al (2016, p. 89) conceituam a monitoria como “[...] uma modalidade de ensino e aprendizagem que contribui para a formação integrada do aluno nas atividades de ensino, pesquisa e extensão dos cursos de graduação".

O monitor consegue assimilar no início de sua formação as práticas docentes, desde a elaboração de planos de aulas até os debates na sala de aula. A monitoria acadêmica é vista como a base inicial do processo de aprendizagem do aluno-monitor, visto que elas consistem em atividades de ensino desenvolvido pelo aluno-monitor em conjunto com o professor-orientador. Dessa forma, Vicenziet al (2016, p.90) afirmam que "o aluno monitor tem a oportunidade de conhecer melhor a disciplina escolhida, permitindo assim um benefício mútuo entre ele, o professor orientador e aos alunos que dela participam".

Nesse sentido, uma formação voltada à docência se faz importante pela necessidade de conhecimento, domínio das rotinas acadêmicas e das práticas de ensino, que são possíveis pela vivência em programas como a monitoria de disciplina ainda na formação inicial. A falta delas pode acarretar menos habilidades, menos comunicação em sala de aula, embora se reconheça a importância de saberes específicos para o exercício da profissão de professor no ensino básico. Gonçalves et al (2021, p. 7) mencionam que:

Entendemos que a monitoria se constitui em oportunidade de aprendizagem e de crescimento coletivo na medida em que proporciona a vivência da concepção do professor reflexivo. Em determinados aspectos o professor tem mais conhecimento e experiência que o monitor e utiliza-os para justificar suas práticas e posicionamentos. Por outro lado, o monitor também constrói, em diferentes situações de aprendizagem, na universidade ou fora dela, conhecimentos e experiências que permitem colaborar com o trabalho docente. Muitas vezes, por exemplo, os estudantes universitários possuem mais competência para trabalhar com os recursos midiáticos e de informática do que o professor, colaborando assim para o emprego das novas tecnologias na sala de aula. Apesar das diferenças, a relação dialógica estabelecida entre o professor e o monitor acerca da realidade e dos desafios da prática docente, os coloca na condição de colaboradores e de aprendizes que, conforme suas especificidades, soma para imprimir mais qualidade ao trabalho educativo.

A monitoria pode ser vista, portanto, como uma oportunidade para que muitos alunos do 
cursolicenciatura em Geografia, e demais ciências, possam exercer a profissão de professor com mais autonomia e criticidade no futuro. Porém, esse programa não titula o aluno como docente especificamente, pois este apenas exercerá o papel de auxiliador em sala de aula. Estimula o discente o gosto pelo ensinar e, principalmente, permitindo a troca de experiências e aprendizagens entre o professor-orientador e aluno-monitor. Além disso, esse programa universitário incentiva a formação dos discentes, proporcionando a eles, hábitos mais efetivos em sala de aula.

A habilidade que cada docente deve desenvolver é a de utilizar adequadamente as técnicas e métodos de ensino conforme as diversas e diferentes situações em que o ensino ocorre, o que necessariamente implica a criação de novas práticas pedagógicas. Dessa forma, as monitorias de disciplinas tornam-se importantes para o desenvolvimento acadêmico, dado que o aluno-monitor poderá vivenciar a vida docente diretamente em sala de aula, possibilitará participar de debates de textos científicos com a turma e elaborar juntamente com o professor-orientador a construção de planos de aulas.

Na medida em que a formação inicial de futuros professores se correlaciona com o programa, a busca de novos conhecimentos e metodologias para facilitar o processo de ensino e aprendizagem passa a ser importante para o planejamento de cada etapa da vida acadêmica, ao produzir uma intervenção decisiva, para saber exatamente o que realizar com os alunos. As dinâmicas que cada projeto pedagógico apresenta como procedimentos metodológicos, são muito importantes para mostrar que estes meios são essenciais para promover, aos professores, novas maneiras de ensinar e, aos alunos, novas formas de aprender.

No tocante programa, pôde-se participar durante o ano de 2020 a experiência vivenciada na disciplina de "Recursos didáticos para o ensino de Geografia" no Ensino Remoto Emergencial (ERE) durante o isolamento social, cuja disciplina estava constituída por 59 aluno(a)s matriculado(a)s e doisalunos-monitores, nesse caso, estes tornaram-se essenciais para a elaboração do andamento das aulas, que foi realizado em conjunto com a professora-orientadora.

Durante as aulas da disciplina, foram realizadas propostas didático-pedagógica com o auxílio de recursos digitais, como a aplicação do jogo Kahoot no processo de ensino e aprendizagem dos alunos acerca dos conteúdos ministrados pelo professor. Sousa, Lopes e Viana (2021, p. 36) definem o jogo como uma “[...] plataforma de aprendizagem online e está baseado em pequenos testes de múltipla escolha, sendo que a sua aplicação varia conforme os objetivos de cada professor, podendo ser acessado pelo computador ou pelo celular".

Nesse sentido, o jogo foi aplicado pelos monitores no intuito de sistematizar os conteúdos já repassados durante as aulas, obtendo bons resultados em relação à assimilação e participação dos alunos 
da disciplina, nesse sentindo, a monitoria foi de suma importância, pois possibilitou a participação de todos durante a aula, a prática pedagógica por intermédio de outros recursos, a exemplo do jogo Khaoot, ademais a utilização dessa ferramenta serviu para estimular os alunos a realizarem a leitura prévia dos textos, logo em seguida aplicou-se o jogo (figura 3):

Figura 3 - Aplicação do jogo Kahoot aplicada pelos alunos-monitores durante a disciplina de "Recursos didáticos para o ensino de Geografia" da UFPI, ministrada no período de 2020.3.

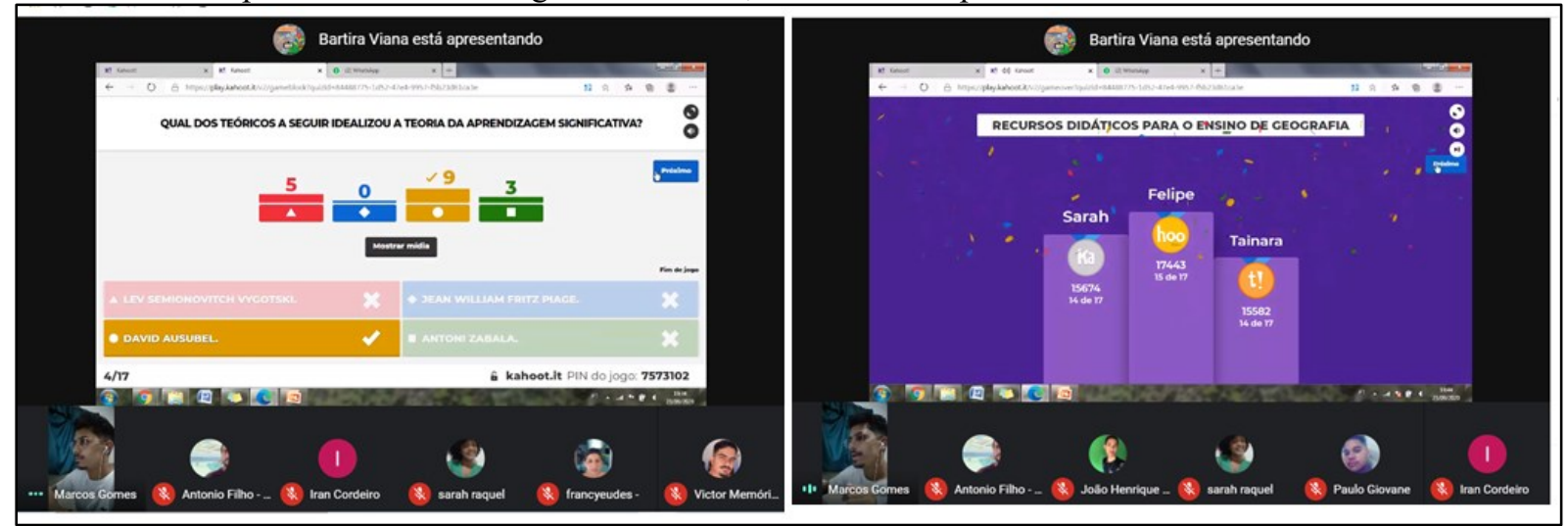

Fonte: Sousa (2020)

De uma forma geral, as monitorias acadêmicas de disciplinas das universidades públicassão grandes incentivadores na formação inicial de futuro(a)s docentes, a exemplo da monitoria ofertada pela coordenação do curso de Geografia intitulada de Recursos didáticos para o ensino de Geografia. Aatividade estimulou habilidades como o desenvolvimento da oratória ao discutir textos científicos, realização de atividades extracurriculares, busca do conhecimento e da autonomia nas aulas da disciplina na qual o (a)aluno (a) está sendo monitor. Dessa forma, foi possível perceber o quanto o programa se torna essencial para o desenvolvimento acadêmico do discente de Geografia.

A monitoria instiga o aluno a ser responsável, a trabalhar em equipe (aluno-monitor, professororientador e a turma), em muitos casos, tal programa oferece auxílio financeiro, no intuito do alunomonitor utilizar com gastos pessoais (alimentação, transporte, xerox e compras de materiais acadêmicos), ou seja, o recurso financeiro torna-se uma forma de incentivar e a se engajar na função de monitor. Além disso, a monitoria possibilita ao monitor inserir as horas de trabalho na comprovação de atividades complementares no sistema da instituição.

Outra vantagem em participar da monitoria acadêmica de disciplina, é o fato da aquisição de novas experiências e aprendizagens, uma vez que facilitará os estudos e impulsionará uma formação docente mais eficiente. Ademais, a monitoria permite o enriquecimento do currículo do estudante, por isso, pode ser útil e com grande potencial na obtenção de novos conhecimentos e experiências enquanto futuro professor.

Conclui-se assim, quea prática na monitoria se torna, portanto, um espaço de criação e reflexão, 
em que novos conhecimentos são constantemente produzidos e modificados. De acordo com essa discussão, a realidade educacional é muito fluida e reflexiva para permitir uma sistematização técnica. Desse modo, o conhecimento dos profissionais não pode ser visto como um conjunto de técnicas ou como um kit de ferramentas para a produção da aprendizagem, daí a importância que a monitoria detém para a formação inicial, sobretudo, para a relação com a teoria e prática na sala de aula.

\section{CONSIDERAÇÕES FINAIS}

Existem vários programas nas universidades públicas brasileiras como a extensão universitária, PIBID, Residência Pedagógica e Monitoria de disciplina, os quais atuam com diferentes metodologias e ferramentas de pesquisa. Eles incentivam o(a)s graduando(a)s em licenciaturas a permanecerem no curso e estimula o senso crítico acerca do seu desenvolvimento enquanto futuro(a)s docentes de Geografia.

Cabe ainda notar que, como discutido ao longo desteartigo, os programas na sua maioria apresentam limitações pois restringem-se a um número pequeno de integrantes, com exceção das açõesde extensão que estão presentes nas mais diversas categorias do ensino superior, como por exemplo, licenciaturas, bacharelados, especializações e outros. Outro aspecto que se faz um obstáculo para muitos do(a)s estudantes nos programas é o fato de serem poucas as bolsas remuneradas, que na sua maioria são as mais concorridas, pois proporcionam aos discentes apoio financeiro ao longo da duração de sua atuação.

Outro dilema, é o fato de muitas escolas participantes apresentarem muitos desafios quanto à adequação do planejamento, elaboração e execução do plano de ação a serem ofertadas pelos programas como o PIBID e RP. Como por exemplo, dispersão do(a)s aluno(a)s na disciplina de geografia por ser caracterizada por muitos como uma ciência minemônica, falta de materias didáticos, questões estruturais da escola e também por problemas da inclusão digital, devido a nova realidade de ensino, o Ensino Remoto Emergencial (ERE).

A Universidade tem como objetivo formar profissionais que trazem funções essenciais para o funcionamento e a competitividade no mercado de trabalho. Dessa forma, as universidades públicas e de iniciativa privada adotam posturas, atitudes, opiniões, projetos, assistência, auxílio, visões de mundo e contradições político-sociais que se divergem ou convergem a fim de trazer diversas contribuições através de várias percepções de mundo.

Percebeu-se a ocorrência de muitas discussões a respeito da formação inicial nas IES, desde a sua inserção no campo de pesquisas científicas, sua permanência e o seu desenvolvimento na escola, que por meio de projetos e programas que fazem com que muitos discentes busquem novas técnicas, novos recursos didáticos e novas propostas pedagógicas, tornando suas futuras aulas ricas em conhecimentos e 
de novas experiências

Sendo assim, os programas universitários possuem grande poder para conectar o(a)s discentes, beneficiados, a prática na sua área de formação, no sentido de que possam internalizar experiências próprias acerca daquilo que optaram para sua carreira em construção. À vista disso, destaca-se que há casos de aluno(a)s que desistem dos programas por incompatibilidade com as múltiplas realidades das escolas públicas e privadas, em que o universitário percebe, às vezes tardiamente, que não está preparado para o fazer docente, ou que esta não é a profissão que almeja.

Este artigodiscutiu as principais contribuições possíveis de alguns programas e projetos presentes nas IES no âmbito da formação inicial,ou atitudes e ações às quais os educadores devem estar atentos durante a prática educativa, tendo como exemplo as experiências adiqueridas pelosautores, discentes do curso de Geografia da UFPI. Ao longo da permanência dos alunos em programas institucionais, é premente instituir práticas dialógicas para a ação docente, pois, caso contrário, a escola continuará sendo, grande parte dela, uma mera reprodutora de conteúdos.

Assim, as interações do(a)s aluno(a)s com o meio escolar e com os docentes em formação passam a retratar a tentativa de mudança de postura, em que se busca construir uma prática além do pensamento sobre o outro, por meio das interações das práticas vividas na escola através dos programas discorrido neste artigo. Dessa forma, para que o(a)docente seja um(a) eficiente mestre em sala de aula, precisará de auxílio acadêmico, seja ele do ponto de vista teórico ou prático, além de sua própria experiência pessoal.

\section{REFERÊNCIA}

BRASIL, CAPES. Programa Residência Pedagógica, 2018. Disponível em: https://www.gov.br/capes/pt-br/centrais-de-conteudo/28022018-portaria-n-38-institui-rp-pdf. Acesso em: 11 jun. 2021.

BRASIL, Portaria no 7.219, de 24 de junho de 2010, Brasília, DF, 2010. Disponível em: http://www.planalto.gov.br/ccivil_03/_Ato2007-2010/2010/Decreto/D7219.htm. Acesso em: 10 jun. 2021.

BRASIL. CAPES. Programa Residência Pedagógica, 2020. Disponível em: http://uab.capes.gov.br/educacao-basica/programa-residencia-pedagogica. Acesso em: 08 nov. 2020.

BRASIL. CAPES. ProgramaInstitucional de Bolsa de Iniciação à Docência - PIBID, 2020. Disponível em: https://www.gov.br/capes/pt-br/centrais-de-conteudo/06012019-edital-2-2020-PIBIDpdf. Acesso em: 08 jun. 2021.

BULGRAEN, Vanessa Cristina. O papel do professor e sua mediação nos processos de elaboração do conhecimento. Revista Conteúdo, Capivari, v.1, n.4, p. 30- 38, ago./dez. 2010. Disponível em: http://www.moodle.cpscetec.com.br/capacitacaopos/mstech/pdf/d3/aula04/FOP_d03_a04_t07b.pdf. Acesso em: 08 jun. 2021. 
FERRO, Maria da Glória Duarte; GUEDES, Neide Cavalcante. Formação e prática docente: Articulação necessária para a mudança educativa. In: FERRO, Maria da Glória Duarte; ARAUJO, Francisco Antonio Machado. (org.). Docência e pesquisa em formação de professores: Primeiras aproximações ao objeto de estudo. Teresina: EDUFPI, 2018. p. 17-47.

FREITAS, Mônica Cavalcante; FREITAS, Bruno Miranda de; ALMEIDA, Danusa Mendes. Residência pedagógica e sua contribuição na formação docente. Ensino em Perspectivas, Fortaleza, v. 1, n. 2, p. 112, 2020. Disponível em: https://revistas.uece.br/index.php/ensinoemperspectivas/article/view/4540. Acesso em: 11 jun. 2021.

Gonçalves, Mariana Fiuza et al. A importância da monitoria acadêmica no ensino superior. Revista pemo. Ceará, v. 3, n. 1, p. 1-12, 2021. Disponível em: https://revistas.uece.br/index.php/revpemo/article/view/3757. Acesso em: 11 jun. 2021.

NUNES, Lúcia Maria de Sousa Leal; LIMA, Maria da Glória Soares Barbosa. Formação docente e prática: Território e encruzilhadas de produção de conhecimento. In: FERRO, Maria da Glória Duarte; ARAUJO, Francisco Antonio Machado. (org.). Docência e pesquisa em formação de professores: Primeiras aproximações ao objeto de estudo. Teresina: Edufpi, 2018. p. 49-64.

SANTOS, Luline Silva Carvalho; MENEZES, Pricylla Karoline de; BENTO, IzabellaPeracini. Formação Inicial de Professores de Geografia e o contexto das orientações curriculares atuais. In: ROSA, Claudia do Carmo; BORBA, Odiones de Fátima; OLIVEIRA, Suzana Ribeiro Lima. (org.). Formação de Professores e ensino de Geografia: Contextos e perspectivas. Goiânia: C\&A Alfa Comunicação, 2020. p. 85-106.

SILVA, Lineu Aparecido Paz e. Formação continuada em Geografia: uma análise na rede municipal de ensino em Teresina/PI. 2019. Tese (Doutorado em Geografia) - Programa de Pós-graduação em Geografia. Universidade de Brasília, Brasília, 2019.

SOUSA, Marcos Gomes de. A importância da extensão universitária para o processo de formação inicial em Geografia. Formare, Teresina, v. 8, n. 1, p. 111- 119, jan. 2020.

SOUSA, Marcos Gomes de; ALBUQUERQUE, Emanuel Lindemberg Silva. PIBID como formação inicial à docência: Relatos de experiência na Geografia. Formare, Teresina, v.7, n.2, p. 108-116, jul. 2019.

TARDIF, Maurice. Saberes docentes e formação profissional. 11 e.d. Petrópolis: Vozes, 2010.

VICENZI, Cristina Balensieferet al. A monitoria e seu papel no desenvolvimento da formação acadêmica. Revista ciência em extensão. São Paulo, v. 12, n.3, p. 88-94, 2016. Disponível em: https://ojs.unesp.br/index.php/revista_proex/article/view/1257/1254. Acesso em: 11 jun. 2021.

\section{AGRADECIMENTOS}

Os autores agradecem ao Grupo de Pesquisa em Geografia, Docência e Currículo (GEODOC) e à Universidade Federal do Piauí (UFPI), por meio da Coordenação do Curso de Geografia (CGEO/CCH) 